\title{
The Natural Behavior Debate: Two Conceptions of Animal Welfare
}

\section{Heather Browning}

To cite this article: Heather Browning (2020) The Natural Behavior Debate: Two Conceptions of Animal Welfare, Journal of Applied Animal Welfare Science, 23:3, 325-337, DOI: 10.1080/10888705.2019.1672552

To link to this article: https://doi.org/10.1080/10888705.2019.1672552

曲 Published online: 27 Sep 2019.

Submit your article to this journal $\pi$

Џll Article views: 1265

Q View related articles $\widetilde{ }$

View Crossmark data

Citing articles: 17 View citing articles 진 


\title{
The Natural Behavior Debate: Two Conceptions of Animal Welfare
}

\author{
Heather Browning (1) \\ School of Philosophy, Australian National University, Acton, Australia
}

\begin{abstract}
The performance of natural behavior is commonly used as a criterion in the determination of animal welfare. This is still true, despite many authors having demonstrated that it is not a necessary component of welfare some natural behaviors may decrease welfare, while some unnatural behaviors increase it. Here I analyze why this idea persists, and what effects it may have. I argue that the disagreement underlying this debate on natural behavior is not one about which conditions affect welfare, but a deeper conceptual disagreement about what the state of welfare actually consists of. Those advocating natural behavior typically take a "teleological" view of welfare, in which naturalness is fundamental to welfare, while opponents to the criterion usually take a "subjective" welfare concept, in which welfare consists of the subjective experience of life by the animal. I argue that as natural functioning is neither necessary nor sufficient for understanding welfare, we should move away from the natural behavior criterion to an alternative such as behavioral preferences or enjoyment. This will have effects in the way we understand and measure welfare, and particularly in how we provide for the welfare of animals in a captive setting.
\end{abstract}

\section{KEYWORDS}

Animal welfare; natural behavior; teleological welfare; subjective welfare

\section{Introduction}

Providing for the welfare of captive animals consists largely of understanding what factors contribute to, or detract from, the welfare of these animals. These factors are the conditions for welfare; those things that make the lives of animals better or worse. These include factors such as diet, shelter, health, and behavioral opportunities. To this end, there are animal welfare frameworks in place that function to list the important conditions for animal welfare, allowing best practice in animal husbandry. Possibly the most commonly used framework is that of the Five Freedoms (Farm Animal Welfare Council, 1979). Others include the "Five Domains" (Mellor, 2016), Dawkins' "Two Questions" (Dawkins, 2003) and the Welfare Quality assessment system (e.g., Botreau, Veissier, \& Perny, 2009). All of these list conditions they think are crucial to creating and maintaining good welfare; however, although there is substantial overlap of many components, there is not always agreement as to which criteria should be used within these lists.

One of the most contested criteria for animal welfare is that of natural behavior - that allowing an animal to perform natural behaviors is beneficial to welfare. Within animal husbandry professions, particularly the zoo industry, there is often a strong feeling that promoting natural behaviors is of benefit to the animals. However, there are also strong reasons for thinking this criterion does not do well at capturing exactly why particular behaviors are important for welfare - that is, how they matter to the animal (see discussion in, for example, Dawkins, 1980; Mellor, 2015; Špinka, 2006; Veasey, Waran, \& Young, 1996b, 1996a). Most importantly, it seems like natural behavior lacks a necessary connection to welfare - many natural behaviors will be detrimental to welfare, while some unnatural behaviors can be beneficial. 
In this paper, I will begin in Section 2 by outlining the debate on natural behavior, and the use of the natural behavior criterion, as well as some alternatives that have been proposed. I will then move on in Section 3 to diagnose the disagreement not at the level of which conditions are thought to affect welfare, but at a deeper conceptual level of understanding of the state of welfare itself and what it consists of - a "teleological" understanding of welfare as opposed to a "subjective" understanding. Finally, in Section 4 I will argue that natural functioning fails to be either necessary or sufficient for welfare, and so we should reject the teleological welfare concept and the natural behavior criterion that rests on it, in favor of an alternative like behavioral preferences or enjoyment. I will then describe some of the effects a change like this might have in the way we understand and measure welfare, and particularly in how we provide for the welfare of animals in a captive setting.

\section{The "natural behaviour" debate \\ Use of the natural behavior criterion}

The criterion of natural behavior is one of the most controversial proposed conditions for animal welfare. It is the idea that the performance of natural, or species-typical, behavior leads to increased welfare, and its nonperformance is detrimental to welfare. Within animal husbandry practice and research, most prominently within the zoo industry, natural behavior is often considered as an essential component of welfare. The assumption of natural behavior as necessary for welfare of captive exotic animals is common throughout the literature (e.g., Clubb \& Mason, 2007; Gray, 2017; Hill \& Broom, 2009; Maple \& Perdue, 2013). Assessments of zoo animal welfare often rely on comparisons with wild activity budgets (see examples in Howell \& Cheyne, 2019), where "deviations from wild-type behaviours are assumed to indicate a reduction in welfare" (Howell \& Cheyne, 2019, p. 79). Most environmental enrichment efforts for captive zoo animals are used in an attempt to increase the performance of natural behaviors, without further thought as to whether these are the best way to increase welfare. ${ }^{1}$ Many zoos emphasize "the ability of each animal to perform his or her species-typical behaviour" (Koene, 2013, p. 361). Maple, McManamon, and Stevens (1995) claim, "the exhibition of species-typical behaviour should be the goal of all zoo husbandry programs" (1995, p. 225). Many authors consider performance of natural behavior to be a key indicator of animal welfare (see examples in Duncan and Fraser, 1997), where the lack of natural behaviors is seen as a sign of problematic welfare. Use of this criterion is also common in philosophical discussions of animal welfare (e.g., Nussbaum, 2004; Rollin, 2006).

The natural behavior criterion also appears in some versions of the "Five Freedoms" framework, a set of criteria that are considered to be central components determining animal welfare and which compose one of the earliest frameworks for animal welfare. The Freedoms lay out a set of guidelines for ensuring animal welfare and include the "freedom to express normal behaviour" (Farm Animal Welfare Council, 1979). This criterion is used in two different ways. The first, and the one that is relevant to this paper, is referring to natural behavior. This is either through rephrasing as "freedom to express natural behaviour" (e.g., SPCA NZ, n.d.-b) or as understanding normal behavior to mean natural or species-typical behavior: "a normal behaviour is the way an animal acts in its natural environment" (SPCA NZ, n.d.-a); "normal behaviour is based, in part, on the evolution of animal behaviour in the natural environment of the progenitor species" (Farm Animal Welfare Council, 2009 , p. 12). This usage is particularly common within the husbandry of exotic animals. The second, more common, usage retains the form "freedom to express normal behaviour" and takes this to mean something less strong than natural, such as those behaviors commonly performed by the individual animals within their particular circumstances (e.g., domestication). In those cases where normal behavior is used without any intended connection to natural or species-typical behavior, the concerns outlined in this paper will not apply, though there may still be other reasons to prefer one of the other accounts described, which more closely tie the importance of a behavior to its effects on the animal. 
With the criterion of natural behavior still in common use, there is a problem if it turns out not to actually be linked with animal welfare - with the wrong targets for improving welfare, there is the risk of wasting resources that could be used in other areas with greater effect. In the next section, I will look at some reasons why we should think that this criterion does not do well in capturing a condition for animal welfare.

\section{Problems with the natural behavior criterion}

Despite its prevalent use, there are several problems with the natural behavior criterion as have been widely pointed out by, for example, Dawkins (1980), Veasey et al. (1996b, 1996a), Špinka (2006) and Mellor (2015). The primary reason the criterion of natural behavior is inadequate is that natural behavior does not hold any necessary connection to welfare. By contrast, the components described by other common criteria, such as nutrition or health status, do appear to hold such a connection - an animal is going to suffer without sufficient food, or when in pain. As it stands, this criterion relies on the assumption that an animal will suffer if unable to perform any of its natural behaviors, and presumably if performing any unnatural behaviors. However, there is no reason to think that this is the case.

There are natural behaviors that potentially reduce welfare - those behaviors that reflect the struggle to merely survive, but may be experienced as unpleasant, such as predator-avoidance and fighting behavior (Mellor, 2015). Providing captive animals opportunities to perform these behaviors in environments where these challenges no longer exist is unlikely to enhance their welfare; in fact welfare is more likely to decrease due to the associated fear and distress, and potential physical injury (Mellor, 2015). One example of the mistaken reliance on natural behavior is in the husbandry of captive tigers. As the natural social behavior of wild tigers is to live a largely solitary life, most zoos hold tigers on their own. However, captive tigers appear to do better when housed in pairs than singly, as indicated by voluntary performance of a range of prosocial behaviors (De Rouck, Kitchener, Law, \& Nelissen, 2005). As such the focus on replicating the natural behavior decreases rather than improves their welfare.

There are also unnatural behaviors that do not negatively affect welfare - for example, recent work with orangutan enrichment has provided them with computer gaming devices and they seem to derive great benefit, in terms of cognitive stimulation, from interacting with these (Perdue, Clay, Gaalema, Maple, \& Stoinski, 2012). Animal-computer interaction is an emerging field that looks to provide welfare benefits for animals through decidedly unnatural means (see e.g., Mancini, 2011; Rault, Webber, \& Carter, 2015). Despite being far from natural, these behaviors are improving animal welfare.

All this means that there is no reason to think that it is the "naturalness" of the behavior that is linking it to welfare, as opposed to some other aspect of the behavior. It is these other relevant aspects that we should be targeting, as will be discussed shortly. Dawkins (1983) points out that a behavior being performed by a wild member of the species is insufficient to predict that an animal may enjoy performing this behavior or suffer in its absence - the naturalness does not directly link to the welfare effect. Although natural behaviors may often be beneficial to an animal's welfare, they are not necessarily so. Where they are beneficial, they are so in virtue of some other factor, and this should form the substance of the relevant welfare criterion.

\section{Alternative criteria}

Many writers, noting these problems with the account of natural behavior, have proposed alternative criteria that could be used in considering the behavioral requirements of welfare (e.g., Dawkins, 1983, 1988, 1990; Hughes \& Duncan, 1988; Jensen \& Toates, 1993; Webster, 2016). These responses usually revolve around some concept of behavioral needs, drawing a parallel with the physical needs of animals - as an animal has a need for food or water, so too it has a "need" to perform certain behaviors. In terms of animal welfare, the further assumption would be that as an animal may suffer 
when deprived of a physical need, so too would it suffer comparably if deprived of a behavioral "need". Much of the writing since then about the links between behavior and welfare has been in search of a description of what behavioral needs might consist of, and how we might recognize them. ${ }^{2}$ These responses all look for ways in which we may identify which behaviors are important to the animals that perform them, giving that extra relevant factor which actually influences welfare, over and above naturalness.

The first, and probably most popular account, is that of behavioral preferences (e.g., Dawkins, 1983, 1990, 2003). Dawkins' (2003) "two questions" framework simply sets out the two questions "is the animal physically healthy?" and "does the animal have what it wants?" as sufficient for determining welfare. This type of account gives primacy to the preferences of the animals in determining which behaviors are important to welfare. These are the behaviors that an animal wants to perform, that it will choose under testing and will work for the opportunity to perform. The performance of such behaviors is correlated with positive mental states, while their continued frustration creates negative mental states detrimental to welfare. This type of account has the added advantage of allowing for individual differences between members of a species. Growing research in animal personalities has demonstrated personality differences between animals (e.g., Gartner \& Weiss, 2018) and these differences are likely to impact individual welfare in ways that a natural behavior perspective, with its emphasis on species norms, cannot account for. ${ }^{3}$

Even Webster, one of the original authors of the Five Freedoms account now thinks "freedom of choice" would be a better behavioral criterion for capturing the important aspects of behavior relative to welfare - the ability of an animal to choose those behaviors it prefers, or that create positive experiences (Webster, 2016). Other similar accounts include behavioral motivation (e.g., Hughes \& Duncan, 1988) and behavioral goals (e.g., Jensen \& Toates, 1993). Mellor's (2016) Five Domains model prioritizes those behaviors that are enjoyable, or create positive mental states. Similarly, Howell and Cheyne (2019) recommend "a desirable behavioural profile ... indicative of a positive emotional state" (2019, p. 89). In all of these accounts what is emphasized is the importance of making a direct link from behavior to welfare through what has an effect on the animal, where the resulting behaviors might sometimes be natural and sometimes not.

Despite the convincing work described in demonstrating the inadequacy of the natural behavior criterion, and the proposal of suitable alternatives, this criterion is still in common use throughout animal welfare and husbandry organizations, and this continued use stands in need of explanation. This may simply be a case of theory moving ahead of practice - such as the philosophical literature not having been made accessible to those who work in the field - and perhaps practice would change if awareness were raised. However, it has been decades since some of this literature was released, without significant change. This suggests the problem runs deeper.

In the following section I will describe what I think is motivating this difference in perspective. Those who advocate natural behavior appear to be using a "teleological" conception of welfare, in which naturalness is considered fundamental to welfare, outside of its effects in other areas. Others are instead considering animal welfare from a subjective standpoint - that is, consisting of the positive experience of life by the animal, and where only those factors that affect this experience are important in determining welfare. I will present reasons for rejecting the teleological view, and therefore for rejecting the criterion of natural behavior in favor of something like behavioral preferences or enjoyment.

\section{Two conceptions of welfare}

The debate about natural behavior then seems to be at its heart, a debate about what animal welfare really is. Thinking about animal welfare can occur on different levels. There is a more pragmatic standpoint, in which we are thinking about how we can improve animal welfare, about how we make lives better for our animals. This is based in consideration of the conditions for welfare, as I described earlier - those things such as diet, shelter or behavioral opportunities. These conditions play a causal 
role in improving or decreasing welfare. But we can also think about welfare from a more conceptual perspective. We can think about of how we define the underlying state of welfare - what it is we are even talking about when we speak of welfare. This is the state onto which all other welfare considerations collapse - they will be considered as contributing to welfare only in virtue of their contribution to this state. The conditions for welfare are then those things which cause changes in this underlying state.

On its surface, the natural behavior debate appears to be conducted over whether natural behavior should be accepted as a condition for welfare. That is, whether or not allowing an animal to perform natural behaviors will lead to an increase in welfare, in the same way that changes in diet or housing might. However, I believe the debate really lies on the deeper conceptual level concerning how we define the state of welfare itself - what Fraser, Weary, Pajor, and Milligan (1997) refers to as reflecting the "value-laden presuppositions about what is better or worse for animals" (1997, p. 188). This is a similar distinction to one made by Appleby and Sandøe (2002) between the two questions " 'How should well-being or welfare be defined?' and 'How should well-being or welfare be assessed?' ” (2002, p. 285); in this case what has often appeared be a disagreement over the latter is actually a disagreement over the former.

Mellor (2016) points out that there are still multiple ways of understanding welfare - "during the 30 years since animal welfare emerged as a legitimate area of scientific study no universally endorsed definition of it has emerged" (2016, p. 14). These different conceptions of welfare can lead to different outcomes - for example, Croney and Millman (2007) describe a disagreement on the use of sow stalls between those holding different welfare concepts; in this case the different concepts in play led to either endorsement or rejection of the use of such stalls. It is then clearly important to have the right welfare concept in mind in order to make relevant welfare decisions.

Use of the natural behavior criterion often rests on what I will call a "teleological" conception of animal welfare that takes something like the natural flourishing of an animal to be central to its wellbeing. For example, the Farm Animal Welfare council states that "an animal should be kept in an environment within which its species has evolved and with respect for its nature, or telos" (Farm Animal Welfare Council, 2009, p. 12). By contrast, the "subjective" conception describes the experience of life by the animal as grounding the state of welfare.

The teleological conception of welfare takes welfare to consist of the overall "flourishing" of an animal - that is, being "good of its kind" and functioning as it was "designed" by natural selection. These accounts all take this sort of natural functioning as fundamental to the welfare of animals. Rollin (2006) describes the "telos" of an animal as "a nature that sets it apart from other things ... defined by the functions and aims (not necessarily conscious aims) of the creature" (2006, p. 118). He says that "animals [have] a right to live their lives in accordance with their physical, behavioural, and psychological interests that have been programmed into them in the course of their evolutionary development and that constitute their telos" (2006, pp.300-301), centreing the importance of naturalness to welfare. Fraser (1999) also focuses on the concept of telos, considering it to simply mean that "animals should be allowed to live in a manner for which they are adapted, and to have the type of ontogenic development that is normal for the species" (1999, p. 177). Nussbaum (2004) stresses that "it is good for that being to flourish as the kind of thing it is" (2004, p. 306).

Other authors take the concept of welfare to have several parts, but still containing a teleological component: "Animal welfare is best understood as the promotion of physiological, psychological, and species-specific functioning" (Jones, 2013, p. 18); "that animals should feel well by being free from prolonged or intense fear, pain and other unpleasant states, and by experiencing normal pleasures; that animals should function well in the sense of satisfactory health, growth and normal behavioral and physiological functioning; and that animals should lead natural lives through the development and use of their natural adaptations" (Fraser, 1999, p. 178, italics in original). This sort of multi-component welfare concept, inclusive of teleological welfare, is probably currently the most commonly used concept (see e.g., Mellor, 2016, "three orientations"; Maple \& Perdue, 2013, as well as others referenced here). 
As well as being common in the literature, the teleological conception seems to most closely track the intuitions of the general public on issues of welfare - both Lassen, Sandøe, and Forkman (2006) and Vanhonacker, Verbeke, Van Poucke, and Tuyttens (2008) found that citizens were more likely than animal husbandry professionals to consider natural behavior or living a natural life as central to welfare. It is also often a key part of opposition to keeping animals in captivity. See for example, Jamieson (1985) - "it is surely true that in being taken from the wild and confined in zoos, animals are deprived of a great many goods. For the most part they are prevented from gathering their own food, developing their own social orders and generally behaving in ways that are natural to them" (1985, p. 97).

The concept of teleological welfare in animals is closely related to the view of perfectionism in human wellbeing (Appleby \& Sandøe, 2002). Under this view, the goal of human living is to flourish according to our human nature or essence and a good life must necessarily include some objective goods to this end, such as knowledge, achievement or social connections (Wall, 2017).

By contrast, the subjective conception of welfare considers welfare to consist solely of the subjective experience of life by the animal - the total of positive and negative mental states that may be created by various conditions. The subjective case thus relies on the mental states of an animal. ${ }^{4}$ An animal with good welfare is one that experiences primarily positive mental states, while an animal with poor welfare is one that experiences an excess of negative mental states. Welfare is then the positive experience of life by the animal - "the experiential quality of their life, as considered over time" (Regan, 1983, p. 96). This view is used by many of the key writers in animal ethics and welfare science such as, for example, Singer (1995), Regan (1983), Grandin and Johnson (2009), Dawkins (1980), Mellor (2016) and Webster (1994).

The teleological and subjective conceptions of welfare represent the two most common ways of describing what the state of animal welfare consists of - natural functioning, or subjective experience. Although these approaches often overlap, they do not always, and it is important in these cases that we identify which is the more fundamental concern to track. Which one we accept will make a difference not only in terms of how we understand welfare, but also in how we measure it, and in what conditions we take to be important for creating optimal welfare. The use of the natural behavior criterion relies on the acceptance of a teleological welfare concept; as without it, the criterion loses its justification. In the next section, I will look at why we should reject the teleological view as natural functioning is neither sufficient nor necessary for animal welfare, and should thus prefer some other replacement behavioral criteria for welfare.

\section{Why we should reject teleological welfare}

The teleological conception of welfare relies on a link between natural functioning and welfare. Thus in order to accept a teleological conception of welfare, we would need to establish that natural functioning is either sufficient for or necessary for welfare. However, as I will argue, neither of these conditions hold and we therefore have no reason to prefer a teleological view of welfare.

\section{Natural functioning is not sufficient for welfare}

Teleological considerations and natural functioning are not sufficient for welfare. In order to be sufficient, it would need to be the case that naturalness is all that is required for welfare. However, there are plenty of cases in which we might have naturalness without having welfare. For example, take plants, which are typically thought to lack sentience (though see recent work questioning this assumption e.g., Calvo, Sahi, \& Trewavas, 2017). A plant can be fully natural, but does not have a welfare; something more than naturalness is clearly required. Any object is capable of being "good of its kind", but we do not wish to describe these in terms of welfare, with the moral importance we assign to considerations of welfare or well-being. Although some adherents to this view will reply either that we do (or should) have this kind of concern about 
other classes of organisms, or that welfare is insufficient for moral consideration (Appleby \& Sandøe, 2002), this goes against common usage and intuitions about welfare and morality and is not a frequently held view (Duncan, 2002). Thus we require something further to determine welfare, to capture why we are concerned with the welfare of animals and not plants, which can also have better or worse physical functioning.

This something extra is subjective experience. Indeed, it seems to be subjective experience that creates welfare. This is something which is emphasized in the work of Dawkins $(1988,1990,1998))-$ that animal welfare concerns the subjective experiences of animals, in particular their suffering. Fraser (1999) states that "the study of animal welfare is at least partly an attempt to understand the animal's own perceptions of its quality of life" (1999, p. 183). It is the states of pleasure or suffering that make animal welfare matter. It is why most people would consider it problematic to pull the ear off a cat in a way that we don't when we pull a branch off a tree: "they are aware of how they feel and it matters to them" (Webster, 1994, p. 249). Non-sentient organisms may have a "good" in a weaker sense, one that could still be considered in moral decision-making, but sentience provides the strong unique moral claim that grounds welfare. We cannot have welfare with teleology alone, without subjective experience.

We can also see that natural functioning is insufficient for welfare, when considering a sentient organism that can be fully natural, yet still have poor welfare, as discussed in Section 2.2. Animals which are experiencing starvation, disease or predation are living completely natural lives and yet do not have good welfare, demonstrating that there is something else needed, such as positive experience, in order to ensure welfare.

\section{Natural functioning is not necessary for welfare}

Natural functioning is thus clearly insufficient for describing welfare. Those in favor of teleological welfare appear to accept this conclusion, as indicated by the inclusion of subjective and sometimes physical welfare within a multi-factor concept. Even in the case of human views on perfectionism, it is common to include a component of subjective well-being or the pursuit of pleasure on the list of those human capabilities necessary for flourishing (Bradford, 2017). However, perhaps natural functioning is still a necessary component of welfare; so that we are unable to understand welfare without it. It would be necessary for welfare if, in all cases of good welfare, there is the presence of naturalness, and if the absence of naturalness leads to poor welfare. In this case, we could then instead use a conception of welfare that encompasses at least both subjective and teleological aspects, such as the multi-component frameworks described earlier (Fraser, 1999; Jones, 2013; Maple \& Perdue, 2013).

Unfortunately, these conditions do not seem to hold. As described, there are many cases in which naturalness is present but in which welfare is still poor. By contrast, there are plenty of cases in which naturalness is significantly reduced, or absent, but in which welfare is still good. Some examples, such as use of technology for enrichment, were discussed in Section 2.2. Other examples include husbandry interventions such as veterinary treatment, analgesia or reproductive control (Yeates, 2018). A captive animal may be unnatural in many ways, yet still having a positive experience of life under which it seems odd to claim that it is suffering a compromise in welfare. We would require additional evidence that the animal is suffering in the absence of natural environments or behavioral expressions (Howell \& Cheyne, 2019).

Arguments in favor of the necessity of teleology, or naturalness, as necessary for welfare generally occur in the form of thought experiments, describing cases in which we have strong intuitions about welfare when naturalness and subjective welfare come apart. We may imagine an animal that meets all the subjective and physical criteria for welfare, but that we still wish to say is not experiencing best welfare. Here I will describe such a case and provide an alternative explanation for our intuitions about it, without the need to appeal to teleological welfare. 
An example case of this kind is the "torpid tiger". ${ }^{5}$ Tigers can be challenging for zoo managers, as they are wide-ranging carnivores that can become frustrated if unable to perform roaming, hunting and killing behaviors (Szokalski, Litchfield, \& Foster, 2012). This frequently manifests in pacing, and tigers are often seen moving up and down a single fence of their exhibit on what is clearly a wellworn path. Now we imagine that one zoo manager, eager to combat this obvious welfare issue in tigers, begins a breeding program. They select only the quietest tigers, those that seem to prefer sleeping to roaming or hunting. After a few generations, they have created the "torpid tiger". This animal shows no desire to hunt or kill, as evidenced by its lack of interest in enrichment items designed to channel these behaviors. It does not pace, instead choosing to rest and sleep throughout its days, rousing only to eat when necessary.

It seems this animal has very good subjective welfare - it has what it wants and its mental states are all positive (we will also assume here that the animal does not suffer any lack of physical condition due to its sedentary lifestyle, that may cause discomfort or disease and impact its welfare in this way). And yet, our instinct is that there is something wrong with this picture. There is something lost in the "tigerness" of this animal. It is less natural, and perhaps does not have ideal welfare. There are two lines of response to this case. The first is to deny that there is any real problem with welfare, claiming instead that the problem simply lies within our own expectations. The second is to identify the lack not within the tiger itself, but in where we set our baseline - by what standards we judge the "best" level of subjective welfare.

In the first instance, it seems entirely possible to refute that there is a welfare problem here at all. Perhaps our intuitions are just incorrect. Rather than our feeling of "wrongness" reflecting any welfare problem with our torpid tiger, it simply reflects our own biases - as Rollin (2006) puts it, "a queasiness that is at its root aesthetic" (2006, p. 128). We are conditioned to seeing tigers in particular ways, to enjoying certain features of them. When we see a tiger that lacks these features, we are disappointed. This certainly seems to be the case with the multitude of zoo visitors who constantly express their dismay at seeing sleeping animals, apparently unaware that most animals particularly big cats - also spend the majority of their time in the wild sleeping. The problem lies not with the welfare of our perfectly content tiger, but simply in our own categorizations of what animals should be like. Indeed, it seems that the burden of proof may rest on the shoulders of those who feel troubled, to justify why it is that the perceived problem is one of poor tiger welfare, rather than, say, a human concern with esthetics, or the ethics of manipulating tiger lives.

This response may still be unsatisfying. It does not get to the heart of our feeling that there is a problem in welfare - that this animal is not experiencing welfare as high as it should be. In response, we need to examine where we set our baseline for welfare. It is not enough to simply say that an animal is perfectly content within itself - that it doesn't know any differently. What we really want is a comparison between this animal in its current situation and its best possible situation. Although the torpid tiger is not experiencing any suffering, and is content with its days of sleeping, there may be a range of positive mental states it is lacking, those associated with achieving the goals of hunting or killing. Even if the tiger would not choose these activities, it does not follow that it would gain no subjective benefit from them - the activities we select are not always those which bring us the greatest pleasure. If we simplify welfare into something like "happiness units", it could turn out that the number of obtainable units for a torpid tiger are not as many as it could otherwise have had if it had been different. Activities like sleeping might bring fewer units of happiness, in the form of contentment, while other behaviors might bring higher levels of happiness. If as discussed earlier, feelings of pleasure are often tied to more strongly fitness-enhancing behaviors, a more active tiger is more likely to experience these. The torpid tiger is then said to have reduced welfare, not because it is suffering, but because it is not in the best possible state it can be in.

Even if this tiger might be experiencing its best possible welfare in terms of the maximum happiness it can obtain, we may think we have harmed its welfare by creating it such that it can only obtain this reduced level of happiness. There is a welfare problem for our torpid tiger if its experience of subjective welfare is lower than that of a traditional tiger that has its needs met. 
A content torpid tiger may still have better welfare than a frustrated traditional tiger. But it does not have welfare as high as a content traditional tiger, and thus has in some way been harmed. It is our suspicion that this may be the case that leads us to see a welfare problem with our torpid tiger. The welfare may be reduced, but what is missing is not any kind of "naturalness", merely the potential positive mental states associated with some behaviors. Our intuitions can be explained within a framework of subjective welfare, without the need to invoke teleology.

When thinking about multi-component frameworks for welfare, it is extremely unclear just what teleology is supposed to add - if the leading of a natural life adds to neither an animal feeling well nor functioning well, it is not obvious what further welfare benefit is gained simply through the presence of "naturalness". We may think that many natural behaviors will be associated with positive mental states in an animal and so add to welfare. However, in this case it is not the concept of naturalness that is doing the work. It seems that these accounts only work if welfare is defined to include this component of naturalness, but there is no further work done to convince us as to why this is useful. It is instead to be taken as fundamental, without further justification beyond mere intuition. As the teleological element does no work in determining animal welfare, it is thus unnecessary for an understanding of welfare.

\section{Explaining reasons for the belief}

I have argued that there are good reasons to think natural functioning is neither sufficient nor necessary for welfare. What, then, has functioned to justify the inclusion of teleological considerations in welfare? This view is still common, and often considered intuitive. Here I will examine some other possible assumptions or intuitions underlying this belief, and argue that they are unrelated to welfare considerations. Identifying the source of the belief, and showing that it does not connect to relevant considerations, acts to undermine the belief itself (Kahane, 2011).

One underlying assumption to this view appears to be that the wild state represents the best possible welfare for animals. This is likely to be based in a romanticized view of nature - as Dawkins (1980) comments, perhaps "we fall into the trap of thinking that a natural life is better simply because it seems more romantic to us from the outside" (1980, p. 52). This is a version of the "appeal to nature" fallacy: the mistaken belief that because something is natural, it must be good. The fact that the teleological conception appears to be most often held by members of the general public lends support to this reading, as they will often not have reflected on the concepts. However, this assumption is clearly dubious, as there are many examples of animals suffering in the wild. Individuals are often physically injured, malnourished, stricken with disease and exposed to unfavorable environmental conditions. In a behavioral sense, it is not the case that wild animals are free to perform all their natural behaviors. Animals suffering from illness or injury will clearly have a more limited behavioral repertoire. Additionally, many subordinate animals will be denied the opportunity to access particular food resources, or mates, through competition with conspecifics, or threat from predators. Animals in the wild are far less free or happy than is commonly assumed.

Another possible driving force behind the teleological conception of welfare seems to be a conflation of welfare with biological fitness (e.g., Barnard \& Hurst, 1996). In the wild, animals have developed a behavioral repertoire that functions to increase fitness. The subjective states of an animal then function as proximate mechanisms to drive particular behaviors (e.g., Baxter, 1983; Dawkins, 1998). The idea is that pleasure or aversion may be adaptive in encouraging animals to change some aspect of their environment - "for example, experiencing the sensation of hunger would inform the animal of a nutritional deficit, but by making the sensation unpleasant the animal is motivated to compensate for the deficit" (Baxter, 1983, p. 212). In the wild then, those states that correspond to welfare are most likely to be those that also correspond to biological fitness. In this case, the two types of welfare may correlate - what is best for the animal's functioning may also provide the best subjective welfare experience. In the case of captivity, they can come apart: the ultimate needs are met, but the proximate mechanisms may still be triggered unnecessarily. Dawkins 
(1988) draws the distinction between real threats to fitness, as may be experienced by the animal, and perceived threats to fitness as a captive animal may experience. It is these perceived threats that may motivate behavior, and simply protecting fitness itself will not be enough to overcome these drives. Those subjective experiences which have evolved as adaptations to promote fitness may be maladaptive in a captive setting. The subjective wellbeing of the animal has become separated from its biological fitness. In captivity, there is no reason to suppose that fitness is linked to welfare and thus this fails to provide support for the teleological view.

There seem then to be strong reasons for rejecting the teleological view as part of our conception of animal welfare, as natural functioning is neither sufficient nor necessary for our understanding of welfare. Additionally, the reasons we have for accepting such a view may be based in mistaken assumptions about the biology and fitness of wild animals, rather than tracking relevant facts about animal welfare.

\section{A place for natural behavior}

I have shown that there is no good reason for accepting a teleological account of welfare over a subjective account, or something similar. There is nothing this adds to our understanding of welfare as it matters to the animal. With this in mind, it is clear that the criterion of "natural behaviour" does not serve as a useful component of captive animal welfare, as it fails to capture what is important about welfare as understood in a more subjective sense. Alongside Yeates (2018), "we can dismiss the idea that natural behaviour is conceptually part of wellbeing: they are logically independent concepts" (2018, p. 5). Instead, we should prefer one of the previously described accounts that better tracks the ways in which particular behaviors matter to the animals, such as Dawkins' work on preferences (e.g., Dawkins, 1983, 1988, 1990), Webster's (2016) suggestion of "freedom of [behavioural] choice" (Webster, 2016, p.3), or Mellor's focus on those behaviors that are enjoyable and promote positive mental states (e.g., Mellor, 2016).

This is not to say that considerations of natural behavior are not useful. Studies of natural behavior certainly have a place in animal welfare. Yeates (2018) outlines a number of ways in which study of natural behavior can assist in understanding and improving welfare. Most importantly, this criterion has emphasized the importance of particular behavioral needs in considerations of animal welfare. In animal husbandry systems where animals that are merely lacking in injury or disease are considered to have sufficient welfare, an emphasis on behavioral requirements is crucial. Natural behavior can also function to help us find those behaviors which might improve welfare, and to serve as an indicator of good welfare.

Knowledge of the behavior of wild counterparts allows us to identify the range of behaviors an animal may want to perform and the circumstances under which this may occur. This can then be used as the basis for further examination into what specific behaviors an animal may suffer in the absence of; which behaviors impact its mental states or physical health. For example, Dawkins (1989) analyzed the time budgets of red junglefowl (Gallus gallus) as a model for domestic fowl (Gallus domesticus). She found that even when fed regularly, the junglefowl still spent a lot of time in foraging activities, which suggested they might be important, and flagged this as a starting point for further testing on domestic fowl. Mellor (2016) suggests that "the natural living orientation remains a reference point by which likely untoward consequences of imposed environmental and other restrictions can be identified and assessed using frameworks that incorporate the two other orientations [physical (biological function) and psychological function (affective state)] as integrated elements" (p. 14). If there is no physical or psychological detriment to the performance or nonperformance of particular behaviors, then there does not seem to be a welfare concern, regardless of the naturalness of the behavior.

When we have limited access to information about the subjective experiences or preferences of an animal, reference to its natural behavior may be a useful shortcut to those things which are likely to 
matter. Špinka (2006) argues that natural behavior can be a useful criterion for animal welfare as it may be the easiest way of meeting the animal's desired ends, provide positive emotions and have longer-term effects on health and welfare that may not be assessed. For example, mink that are allowed the opportunity to play in water will later show more play behavior in their cage (Špinka, 2006). Veasey et al. (1996b) suggest that, all other things being equal, it is probably better for a captive animal to spend its free time performing natural behaviors, and a captive animal performing all relevant wild behaviors is probably (but not definitely) less likely to be suffering than one that is not. Mellor (2015) rejects a strong link between natural behavior and welfare but argues that "an animal which is fully engaged by exploring and food gathering in stimulus-rich environments and by interacting pleasantly with other animals in its social group may experience intrinsic, deeply embedded feelings of reward" (2015, p. 18) and that "natural living is a helpful concept because it points towards the best that such behavioural freedom might achieve affectively on behalf of animals" (2015, p. 18). Although natural behavior may not have a direct link to animal welfare; in most cases it will be a strong guide to identifying those behaviors which are most likely to matter to the animal, which can then be the subject of further study.

The common theme here is that while many natural behaviors may be conducive to, or indicative of, good welfare, what is really important is their impact on the animal and the creation of accompanying positive mental states - without these, the behavior serves no real welfare function. Instead of performance of natural behavior as a criterion of welfare, we then need to attend to which aspects of such behavior may be important to welfare. This allows us to focus on the consideration that should be central in welfare decisions - what it is that matters to the animals themselves.

\section{Conclusion}

In this paper I have argued that the commonly used criterion of "natural behaviour" for animal welfare fails to provide a necessary link to welfare. It is easy to think of cases of "natural" behavior that harm welfare, and cases of "unnatural" behavior that improve it. The case for naturalness as a component of welfare appears to rest on a teleological conception of welfare, that takes welfare to consist, at least in part, of states external to the animal, such as "naturalness" or biological fitness. I argued that such a conception fails to capture what is important about welfare; relying on natural functioning which is neither necessary nor sufficient for understanding or describing the state of welfare. Instead, we should prefer something like a subjective conception of welfare, in which welfare consists of the experience of life by the animal and those factors that affect welfare are simply those which create positive or negative mental states. This will lead us to replace the natural behavior criterion with an alternative behavioral criterion, such as preference or enjoyment, that more closely captures what matters to animal welfare.

The welfare of captive animals is the focus of much research and debate. While significant progress has been made in the understanding of preferred housing and husbandry conditions for captive animals, there is still a long way to go in some areas. Work such as this, seeking to find what components of welfare are most important to the animal itself, can provide assistance in improving the lives of captive animals and encouraging those people involved in animal husbandry to think about what truly are the best conditions for the animals in their care.

\section{Notes}

1. There can be additional reasons aside from welfare to prefer natural behavior for zoo animals - the maintenance of wild behaviors in animals that may be released, as well as the educational benefits to (and esthetic preferences of) the viewing public - but most often they are emphasized for welfare reasons.

2. See Swaisgood (2007) for a useful summary of theories about the relationship between behavior and welfare in this sense.

3. Thanks to an anonymous reviewer for this point. 
4. This means that welfare concerns only apply to those animals capable of experiencing mental states (sentience). Exactly which animals are sentient is then a matter for empirical investigation. See Jones (2013) for an overview on the current state of research in this area.

5. Thanks to Ben Fraser for this example.

\section{Acknowledgments}

Thanks to Kim Sterelny and Ben Fraser for assistance and comments on drafts of this article. Thanks also to three anonymous reviewers, whose detailed comments helped to improve and clarify this manuscript.

\section{Funding}

This research is supported by an Australian Government Research Training Program (RTP) Scholarship.

\section{ORCID}

Heather Browning (D) http://orcid.org/0000-0003-1554-7052

\section{References}

Appleby, M. C., \& Sandøe, P. (2002). Philosophical debate on the nature of well-being: Implications for animal welfare. Animal Welfare, 11(3), 283-294.

Barnard, C. J., \& Hurst, J. L. (1996). Welfare by design: The natural selection of welfare criteria. Animal Welfare, 5(4), 405-433.

Baxter, M. R. (1983). Ethology in environmental design for animal production. Applied Animal Ethology, 9(3), 207-220.

Botreau, R., Veissier, I., \& Perny, P. (2009). Overall assessment of animal welfare: Strategy adopted in welfare quality. Animal Welfare, 18(4), 363-370.

Bradford, G. (2017). Problems for perfectionism. Utilitas, 29(3), 344-364.

Calvo, P., Sahi, V. P., \& Trewavas, A. (2017). Are plants sentient? Plant, Cell \& Environment, 40(11), $2858-2869$.

Clubb, R., \& Mason, G. J. (2007). Natural behavioural biology as a risk factor in carnivore welfare: How analysing species differences could help zoos improve enclosures. Applied Animal Behaviour Science, 102(3-4), 303-328.

Croney, C. C., \& Millman, S. T. (2007). The ethical and behavioral bases for farm animal welfare legislation. Journal of Animal Science, 85, 556-565.

Dawkins, M. S. (1980). Animal suffering: The science of animal welfare. London: Chapman and Hall.

Dawkins, M. S. (1983). Battery hens name their price: Consumer demand theory and the measurement of ethological 'needs'. Animal Behaviour, 31(4), 1195-1205.

Dawkins, M. S. (1988). Behavioural deprivation: A central problem in animal welfare. Applied Animal Behaviour Science, 20(3), 209-225.

Dawkins, M. S. (1989). Time budgets in red junglefowl as a baseline for the assessment of welfare in domestic fowl. Applied Animal Behaviour Science, 24(1), 77-80.

Dawkins, M. S. (1990). From an animal's point of view: Motivation, fitness, and animal welfare. Behavioural and Brain Sciences, 13(1), 1-9.

Dawkins, M. S. (1998). Evolution and animal welfare. The Quarterly Review of Biology, 73(3), 305-328.

Dawkins, M. S. (2003). Behaviour as a tool in the assessment of animal welfare. Zoology, 106(4), 383-387.

De Rouck, M., Kitchener, A. C., Law, G., \& Nelissen, M. (2005). A comparative study of the influence of social housing conditions on the behaviour of captive tigers (Panthera tigris). Animal Welfare, 14(3), 229-238.

Duncan, I. J., \& Fraser, D. (1997). Understanding animal welfare. In M. C. Appleby, \& B. O. Hughes (Eds.), Animal welfare (pp. 19-32). New York: CAB International.

Duncan, I. J. H. (2002). Poultry welfare: Science or subjectivity? British Poultry Science, 43(5), 643-652.

Farm Animal Welfare Council. (1979). Farm animal welfare council press statement. Retrieved from http://webarchive. nationalarchives.gov.uk/20121010012427/http://www.fawc.org.uk/freedoms.htm

Farm Animal Welfare Council. (2009). Farm animal welfare in Great Britain: Past, present, future. Retrieved from https://www.gov.uk/government/uploads/system/uploads/attachment_data/file/319292/Farm_Animal_Welfare_in_ Great_Britain_-_Past_Present_and_Future.pdf

Fraser, D. (1999). Animal ethics and animal welfare science: Bridging the two cultures. Applied Animal Behaviour Science, 65(3), 171-189. 
Fraser, D., Weary, D. M., Pajor, E. A., \& Milligan, B. N. (1997). A scientific conception of animal welfare that reflects ethical concerns. Animal Welfare, 6(3), 187-205.

Gartner, M. C., \& Weiss, A. (2018). Studying primate personality in zoos: Implications for the management, welfare and conservation of great apes. International Zoo Yearbook, 52(1), 79-91.

Grandin, T., \& Johnson, C. (2009). Making animals happy. London: Bloomsbury.

Gray, J. H. (2017). Zoo ethics: The challenges of compassionate conservation. Melbourne: CSIRO Publishing.

Hill, S. P., \& Broom, D. M. (2009). Measuring zoo animal welfare: Theory and practice. Zoo Biology, 28(6), 531-544.

Howell, C. P., \& Cheyne, S. M. (2019). Complexities of using wild versus captive activity budget comparisons for assessing captive primate welfare. Journal of Applied Animal Welfare Science, 22(1), 78-96.

Hughes, B. O., \& Duncan, I. J. H. (1988). The notion of ethological 'need', models of motivation and animal welfare. Animal Behaviour, 36(6), 1696-1707.

Jamieson, D. (1985). Against zoos. Environmental Ethics: Readings in Theory and Application, 5, 97-103.

Jensen, P., \& Toates, F. M. (1993). Who needs 'behavioural needs'? Motivational aspects of the needs of animals. Applied Animal Behaviour Science, 37(2), 161-181.

Jones, R. C. (2013). Science, sentience, and animal welfare. Biology \& Philosophy, 28(1), 1-30.

Kahane, G. (2011). Evolutionary debunking arguments. Nô̂s, 45(1), 103-125.

Koene, P. (2013). Behavioral ecology of captive species: Using behavioral adaptations to assess and enhance welfare of nonhuman zoo animals. Journal of Applied Animal Welfare Science, 16(4), 360-380.

Lassen, J., Sandøe, P., \& Forkman, B. (2006). Happy pigs are dirty! - Conflicting perspectives on animal welfare. Livestock Science, 103(3), 221-230.

Mancini, C. (2011). Animal-computer interaction: A manifesto. Interactions, 18(4), 69-73.

Maple, T. L., McManamon, R., \& Stevens, E. (1995). Defining the good zoo: Animal care, maintenance and welfare. In M. Hutchins, E. Stevens, \& T. L. Maple (Eds.), Ethics on the Ark (pp. 219-234). Washington: Smithsonian Institution Press.

Maple, T. L., \& Perdue, B. (2013). Zoo animal welfare. Berlin: Springer.

Mellor, D. J. (2015). 1. Positive animal welfare states and reference standards for welfare assessment. New Zealand Veterinary Journal, 63(1), 17-23.

Mellor, D. J. (2016). Updating animal welfare thinking: Moving beyond the "five freedoms" towards "a life worth living". Animals, 6(3), 21.

Nussbaum, M. (2004). Beyond "compassion and humanity". In C. Sunstein \& M. Nussbaum (Eds.), Animal rights: Current debates and new directions (pp. 299-320). New York: Oxford University Press.

Perdue, B. M., Clay, A. W., Gaalema, D. E., Maple, T. L., \& Stoinski, T. S. (2012). Technology at the zoo: The influence of a touchscreen computer on orangutans and zoo visitors. Zoo Biology, 31(1), 27-39.

Rault, J.-L., Webber, S., \& Carter, M. (2015). Cross-disciplinary perspectives on animal welfare science and animal-computer interaction. Proceedings of the 12th International Conference on Advances in Computer Entertainment Technology, 1-5. Iskandar, Malaysia: ACM.

Regan, T. (1983). The case for animal rights. London: Routledge \& Kegan Paul.

Rollin, B. E. (2006). Animal rights and human morality (3rd ed.). New York: Prometheus Books.

Singer, P. (1995). Animal liberation (2nd ed.). London: Plimlico.

Špinka, M. (2006). How important is natural behaviour in animal farming systems? Applied Animal Behaviour Science, $100(1-2), 117-128$.

SPCA NZ. (n.d.-a). Freedom to express normal behaviour. Retrieved from SPCA NZ website: https://kids.spcaeduca tion.org.nz/animal-care/cows/freedom-to-express-normal-behaviour/

SPCA NZ. (n.d.-b). SPCA Blue Tick ${ }^{\otimes}$ The five freedoms. Retrieved from SPCA NZ website: http://spcabluetick.org.nz/ About-us/The-Five-Freedoms

Swaisgood, R. R. (2007). Current status and future directions of applied behavioral research for animal welfare and conservation. Applied Animal Behaviour Science, 102(3-4), 139-162.

Szokalski, M. S., Litchfield, C. A., \& Foster, W. K. (2012). Enrichment for captive tigers (Panthera tigris): Current knowledge and future directions. Applied Animal Behaviour Science, 139(1), 1-9.

Vanhonacker, F., Verbeke, W., Van Poucke, E., \& Tuyttens, F. A. M. (2008). Do citizens and farmers interpret the concept of farm animal welfare differently? Livestock Science, 116(1-3), 126-136.

Veasey, J. S., Waran, N. K., \& Young, R. J. (1996a). On comparing the behaviour of zoo housed animals with wild conspecifics as a welfare indicator. Animal Welfare, 5, 13-24.

Veasey, J. S., Waran, N. K., \& Young, R. J. (1996b). On comparing the behaviour of zoo housed animals with wild conspecifics as a welfare indicator, using the giraffe (Giraffa camelopardalis) as a model. Animal Welfare, 5, $139-153$.

Wall, S. (2017, Winter). Perfectionism in moral and political philosophy. In E. N. Zalta (Ed.), The stanford encyclopedia of philosophy. Retrieved from https://plato.stanford.edu/archives/win2017/entries/perfectionism-moral/

Webster, J. (1994). Animal welfare: A cool eye towards Eden. Oxford: Blackwell Science.

Webster, J. (2016). Animal welfare: Freedoms, dominions and "a life worth living". Animals, 6(35), 1-6.

Yeates, J. (2018). Naturalness and animal welfare. Animals, 8(4), 53. 